Article

\title{
Epistemic Overconfidence in Algorithmic News Selection
}

\author{
Mariken van der Velden * and Felicia Loecherbach \\ Department of Communication Science, Vrije Universiteit Amsterdam, The Netherlands; \\ E-Mails: m.a.c.g.vander.velden@vu.nl (M.v.d.V.), f.loecherbach@vu.nl (F.L.) \\ * Corresponding author \\ Submitted: 9 February 2021 | Accepted: 30 August 2021 | Published: 18 November 2021
}

\begin{abstract}
The process of news consumption has undergone great changes over the past decade: Information is now available in an ever-increasing amount from a plethora of sources. Recent work suggests that most people would favor algorithmic solutions over human editors. This stands in contrast to public and scholarly debate about the pitfalls of algorithmic news selection-i.e., the so-called "filter bubbles." This study therefore investigates reasons and motivations which might lead people to prefer algorithmic gatekeepers over human ones. We expect that people have more algorithmic appreciation when consuming news to pass time, entertain oneself, or out of escapism than when using news to keep up-to-date with politics (H1). Secondly, we hypothesize the extent to which people are confident in their own cognitive abilities to moderate that relationship: When people are overconfident in their own capabilities to estimate the relevance of information, they are more likely to have higher levels of algorithmic appreciation, due to the third person effect (H2). For testing those two pre-registered hypotheses, we conducted an online survey with a sample of 268 US participants and replicated our study using a sample of 384 Dutch participants. The results show that the first hypothesis cannot be supported by our data. However, a positive interaction between overconfidence and algorithmic appreciation for the gratification of surveillance (i.e., gaining information about the world, society, and politics) was found in both samples. Thereby, our study contributes to our understanding of the underlying reasons people have for choosing different forms of gatekeeping when selecting news.
\end{abstract}

\section{Keywords}

algorithmic appreciation; algorithmic gatekeepers; algorithmic news selection; third person effect; uses and gratifications

\section{Issue}

This article is part of the issue "Algorithmic Systems in the Digital Society" edited by Sanne Kruikemeier (University of Amsterdam, The Netherlands), Sophie Boerman (University of Amsterdam, The Netherlands), and Nadine Bol (Tilburg University, The Netherlands).

(C) 2021 by the authors; licensee Cogitatio (Lisbon, Portugal). This article is licensed under a Creative Commons Attribution 4.0 International License (CC BY).

\section{Introduction}

Nowadays, information is not only $24 / 7$ available, but also in unprecedented amounts. There are more news outlets and stories than any human could use, from more and more sources. To separate the "signal" from "noise," news is selected by humans-i.e., journalists (e.g., see the seminal work by Shoemaker \& Vos, 2009), friends, but also people who leave similar digital traces (for example, see Gil de Zúñiga et al., 2017)-or automated systems (i.e., algorithms, recommender systems; for an overview, see Nechushtai \& Lewis, 2019). While scholars and pundits discuss the dangers and pitfalls of being drawn into the rabbit hole by algorithmic news selection (e.g., Helberger, 2020), the work by Thurman et al. (2019) and the framework of algorithmic appreciation (Logg et al., 2019) suggest that most people prefer news in general to be selected by algorithmic solutions rather than human editors.

We put forward that these seemingly opposing views emerge because the uses and gratifications of news (Diddi \& LaRose, 2006; Katz et al., 1974; Lee, 2013; $\mathrm{Ng} \&$ Zhao, 2020) are lumped together. The uses and gratifications approach proclaims that "instead of studying 
what media do to people, we should be asking what people do with media, particularly the gratifications they aim to derive from the fare on offer" (Blumler, 2019, p. 1) and focuses on the reasons why people tend to newsfor example to get political information (surveillance) or to be entertained. Using algorithmic news selection to keep up with the latest celebrity gossip or to follow your favorite sports league is less consequential in terms of problematic societal consequences (i.e., polarization, fragmentation) than using algorithmic news selection for getting information about political processes and opinions. However, especially the public discourse is still mainly focused on the negative consequences of news algorithms for fragmentation, polarization, and spread of false information (Harari, 2020; Rose, 2020; Schipper, 2020; Wong, 2020). By now, it has become clear that most of those claims are overstated (Dubois \& Blank, 2018; Geiß et al., 2021)-still, the gut feeling that algorithms are "to blame for it" remains rather persistent in academic and public discourse.

We propose to instead look more closely at people's preferences for news selection mechanisms and argue that (a) gratifications for news usage coincide with preferences for news selectors, and (b) overconfidence in one's own cognitive ability moderates news selection preferences. We assume that when the main aim of news consumption is surveillance-i.e., gathering knowledge, keeping up with political news-the quality, accuracy, and diversity of information is of rather high importance for the user. Therefore, we expect the appreciation for expert (human) judgment to be higher when news is consumed for this gratification compared to the other gratifications of news usage (i.e., passing time, entertainment, and escapism). At the same time, algorithmic solutions of news selection mostly depend on user choices (i.e., past selections, friend circles). We thus propose that in cases of overconfidence in one's own ability to judge the relevance of information, algorithmic gatekeepers (i.e., algorithms that choose which news will be presented where and to whom) offer an easy way to get tailor-made, relevant content, even, or especially, when the aim of news consumption is surveillance. The algorithm amplifies one's own decisions-meaning that for overconfident people it is seen as making "good" choices. The negative public picture of news algorithms in this context can rather be seen as a consequence of a third person effect (Davison, 1983)-believing that others are more affected by negative consequences of algorithms than oneself.

We pre-registered our argument (see Supplementary Material), subsequently conducted an online survey with a sample of 250 US participants, and replicated our study using a sample of 400 Dutch participants (for research compendium, see Supplementary Material). Our expectation that people who consume news for surveillance have lower trust in algorithmic news selection is not supported by the data. However, when additionally including overconfidence in one's own abilities in the model, a significant positive interaction effect between the surveillance gratification (i.e., understanding the world, society, and politics) and overconfidence could be found. People with high levels of overconfidence appreciate algorithmic news selection more, the more they use news for staying up-to-date with political news, the opposite holds for low levels of overconfidence.

Our findings contribute to the understanding of the underlying reasons people have for preferring different forms of gatekeeping when selecting news. Despite their bad image, algorithms mostly help consumers to make decisions easier and faster. They thus play a larger role when looking for news with no particular purpose. Given the amount of information floating around these days, algorithmic solutions to news selection seem here to stay. Better understanding people's motives and characteristics for news consumption, and in particular news selectors, gives insights into what people are searching for when selecting gatekeepers. Our pre-registered and exploratory analyses indicate that there is much to be learned from looking at individual differences when it comes to news consumption, but especially the preference for news selectors. This in turn plays a large role in shaping the information environments of citizens and the relative importance of algorithmic intermediaries-a process in which our study can deliver an important first step.

\section{Causes for Concern, Yet Appreciated: The Paradox of Algorithmic News Selection}

While news consumption has always been influenced by processes of gatekeeping, the enormous amount of information requires to not only select what makes it into the news (since space limitations are far less of a concern), but it also brings up the question of how to make a selection. In this article, we focus on the latter. While it is still (mostly) journalists and editors that decide whether something happening in the world becomes a news article and gets written up - which certainly is a crucial part of the gatekeeping process-the decision of what actually appears on the front page of the online newspaper and gets suggested to users can be done by either editors or via algorithms. Welbers et al. (2018) showed that even when news selection is performed by human editorial teams, they already heavily depend on sources such as news agencies to handle the workload. Still, in this case, news selection resembles rather closely the traditional way seen in printed newspapers: Experts (trained journalists) judging the newsworthiness of articles for the population as a whole. An increasing amount of pre-selection and placement on the page as well as tailor-made personalization, however, is currently done through algorithmic selections-"gate-keeping no longer belongs to journalists or humans exclusively" (Nechushtai \& Lewis, 2019, p. 7). Recommender systems play important roles in the process of algorithmic selection (Karimi et al., 2018; Ricci et al., 2011). Like human editors, they filter information and thereby reduce the information overload placed on news consumers today. 
The pathways through which those algorithms select information have been the object of scholarly and public debates. Algorithmic news selectors allegedly cause "echo chambers" (Sunstein, 2009)-where only information that resembles one's own world view is displayedand/or "filter bubbles" (Pariser, 2011)-where the decisions of the users (often shaped by processes of selective exposure) involuntarily lead to a narrowing of certain dimensions in the selected articles and especially perspectives expressed in the content. Many studies have challenged those assumptions and often found counteracting results (see e.g., Dubois \& Blank, 2018; Geiß et al., 2021), still the narratives of echo chambers and filter bubbles remain persistent and continue to draw attention on a wide scale. At the same time, a recent study by Thurman et al. (2019) suggests that people view algorithms as more neutral compared to editors and recommendations from friends and therefore prefer them for their news selection. Their finding can be seen as in line with more general work on algorithm appreciation (Logg et al., 2019), showing that people often prefer algorithmic to human judgment. Sundar (2008) also refers to this phenomenon as the "machine heuristic," describing the assumption of neutrality and absence of bias in technology and algorithms. Carlson (2019) coins a similar phenomenon with "mechanical objectivity," i.e., people assume that algorithms might be better in making unbiased selections as opposed to humans. Thus, while academic and public debates regarding algorithmically curated news often remain negative, the positive perception of people regarding automated news selection stands in contrast to it. Our article, therefore, sets out to look into better understanding the motivations and reasons people might have for preferring algorithms for news selection while public and academic debate rather should lead to a negative image. We draw on two different explanatory factors for diving deeper into the reasons why people might select one gatekeeper over the other: Uses and Gratifications Theory (UGT) and epistemic overconfidence.

\subsection{Uses and Gratifications}

UGT describes different motives people have for consuming media content (Katz et al., 1974), and has been ample times applied to understand news consumption (see e.g., Diddi \& LaRose, 2006; Lee, 2013; Ng \& Zhao, 2020). The main question this theory tries to answer is: "Why do people become involved in one particular type of mediated communication or another, and what gratifications do they receive from it?" (Ruggiero, 2000, p. 29). Among the main gratifications people use for news consumption, are entertainment, passing time, escapism, and surveillance. Additionally, answering criticisms over the past few decades, it is also important to include the dimension of habitual usage-accounting for the fact that media selection is not necessarily always based on certain (conscious) goals but often happens as part of a routine (checking the news in the morning) without active intentions (Ruggiero, 2000).

One important aspect of UGT is that it cannot only be used to explain "which media to consume, but also how to consume the media content" (Choi, 2016, p. 250). We draw upon this connection between gratifications sought and the mode or pathway of accessing the news. We expect that the reason why people consume news drives their preferences for gatekeepers of the news. Research on UGT so far mostly focused on looking at the type of media (television, newspaper, online) or the specific outlet that is chosen for news consumption (Lee, 2013). Further, some studies show that, in addition to choosing the content or outlet, the mode of getting access to the content can also be influenced by the gratifications sought. It has been studied which gratifications play a role in using social networking sites in general as a pathway for getting the news (Choi, 2016), which motivations influence the usage of news aggregators (Lee \& Chyi, 2015) or using mobile phones as news devices (Li, 2013). However, what we are proposing is to further abstract from different outlets or platforms towards choosing a general mode of gatekeeping for accessing news. This relates less to whether one chooses a newspaper or Twitter but rather to whether the selection of news was made by a human or an algorithm. While we do know that people value algorithms as a selector of the news (Thurman et al., 2019), there are only limited studies that we know of that connect gatekeeping decisions (algorithms vs. humans) with UGT.

We expect that the positive sides of algorithmic news selection-e.g., the ease with which you receive information and reduce information overload (Bozdag, 2013)exceed the negative sides that are mainly highlighted by scholars-e.g., filter bubbles, polarization, etc.-for specific gratifications more than for others. The negative consequences highlighted by scholars are mainly about the UGT's surveillance domain related to political newslearning more about events happening and keeping up with current events. Gathering political knowledge, seeking information, and shaping attitudes towards topics of societal relevance are the main focus of those concerns. However, a large part of news consumption is not centered around those areas: In the Reuters News Report, around a quarter of the US population indicated to be interested in so-called "soft news" (entertainment, lifestyle, sports) to the same amount or even more than in hard news (politics, economics), especially in the younger age groups (Newman et al., 2015). Studies in the US also show that entertainment motivations play a strong role, especially in the online environment (i.e., being the strongest predictor of the usage of news aggregators, political blogs, or usage of social media for news; Lee, 2013). For escapism, passing time, and entertainment the ease at which articles are obtained might be more important while the stakes for the quality of information are lower than for news sought for surveillance reasons. Especially since recommender systems 
are omnipresent and widely used in the entertainment industry for selecting relevant movies, books, and music (i.e., Amazon, Netflix, Spotify), the usage of algorithmic curation in those areas is more widely accepted. As Wölker and Powell (2020) showed, automated sports news content produced by algorithms is perceived as more credible and selected more often compared to human-produced content. We expect that people have more algorithmic appreciation for news when the gratifications sought are escapism, passing time, and entertainment, compared to the surveillance domain since gathering precise information is less important here than fast information selection. Leading to the following expectation:

H1: People will show less algorithmic appreciation for news selection when the gratification sought for news is surveillance compared to the other gratifications (escapism, passing time, entertainment).

\subsection{Epistemic Overconfidence}

In addition, we argue that the relationship between gratifications sought for news is conditional upon the confidence in one's own cognitive ability. Typical for algorithmic news selection is that the main information sources to judge the relevance of a news article for the user are (a) the past actions of the user, or (b) the choice of similar people or friends. When expecting less of a negative influence on oneself, the notion of optimistic bias (being less vulnerable to malicious intents) has often been proposed as playing an important role (Salmon et al., 2019; Wei et al., 2007). This has been coined the "third person effect," which states that people tend to believe that media "have a greater effect on others than on themselves" (Davison, 1983, p. 3).

In psychological terms, the third person effect stems from a need to show that one is less gullible to negative effects to bolster a positive self-concept (Kim, 2018). One's self-conception as being superior to others regarding the gullibility of negative effects can be seen as one main driver of the third-person effect. This directly relates to the notion that people overestimate their own capacities and ability to judge the relevance of information (Nisbett \& Ross, 1980). The phenomenon has mostly been explored by economists and psychologists as the Dunning-Kruger effect (Dunning, 2011). In this study, we opt for another term, epistemic overconfidence, since it relates to not being able to estimate one's cognitive capabilities correctly. Therefore, we use people's ability for cognitive reflection ("epistemic overconfidence") as a moderator to explore individual overconfidence differences ("third person effect") for the effect of UGT on algorithmic appreciation.

$\mathrm{H} 2$ : The more epistemic overconfidence people display, the more algorithmic appreciation they show when the news gratification is surveillance.

\section{Data, Measurement, and Methods}

To examine how people's expected gratifications of news are connected to the selection of different news gatekeepers, we have fielded an original survey with Amazon Mechanical Turk (MTurk) for the US participants. We have collected data from 268 participants. From the work of Coppock (2019), we know that MTurk samples can be skewed in terms of people's party identities. We had no a priori expectations about people's party identities and their preference for algorithms. Yet, we had 19 respondents (7\%) not answering the question. Because this question is asked last in the survey, we will run the statistical tests with and without these respondents, to see if that influences the robustness of the results. In the remainder of our sample, 116 respondents (43\%) identified as Democrats, 70 respondents (26\%) identified as Republican, 55 respondents (21\%) identified as Independent, and 8 respondents (3\%) identified as "something else." We grouped the latter two options into the category "Other," comprising of 58 respondents (22\%), see Figure 4 for the distribution. In addition, we have fielded the same survey with Pollfish to collect 348 Dutch respondents (Pollfish works similar to MTurk, but has enough Dutch participants). The deviation in number from the pre-registered report (see Supplementary Material) is because of 19 people dropping out of the party ID question. Our research compendium with open materials and more information is available in the Supplementary Material. Our data is fairly balanced regarding gender: 275 respondents (42\%) identified as female, 377 respondents (58\%) identified as male. The distribution, split up for the two countries, is visualized in the left panel of Figure 4. Regarding age, our sample has a mean age of 35 , with a standard deviation of 12.59 . This indicates that $95 \%$ of our sample is between 18 and 60 years old, with the oldest participant being 74 . The distribution of age in our sample is visualized in the middle panel of Figure 4.

In our study, we aim to explain people's appreciation for algorithms when selecting news (exact wording can be found in Appendix A in the Supplementary Material). To do so, we asked people to rank order several gatekeepers: (a) traditional editorial teams, (b) algorithmic selection based on your past reading behavior, (c) algorithmic selection based on the behavior or preferences of your friends or people who are similar to you, and (d) being the gatekeeper themselves. This operationalization made a specific distinction between two forms of algorithms (one based on past-read content, one based on similar users), staying in line with different types of news recommendation algorithms currently being used (i.e., content-based and collaborative). Since most people do only have a vague sense of what algorithms are and based on what information they operate this explanation was added. In the future, it might be good to strike a better balance between the categories by adding similar qualifiers for the traditional 
editorial teams to not make it seem as if they pick out news at random compared to algorithms. We asked them to rank them for the four substantive dimensions of news gratifications: (a) to keep up to date with political news (Surveillance); (b) to escape from daily worries (Escapism); (c) to kill time (Pass Time); and (e) to entertain myself (Entertainment). As described in our pre-registered report (see Supplementary Material), we re-coded the ranking variable with 1 if the algorithms options were ranked first, and 0 otherwise. The used scale in the analysis ranges from 0 to 4 , where 4 indicates one ranked the algorithms options first for all four news gratifications, 3 indicates one ranked the algorithms options first for three out of four news gratifications, 2 indicates one ranked the algorithms options first for two out of four news gratifications, 1 indicates one ranked the algorithms options first for one out of four news gratifications, 0 indicates one ranked the algorithms options first for none of the four news gratifications. The mean value of this scale is 1.92 (SD 1.43), with $75 \%$ of the observations between 1 and 3 . This means that on average, people placed an option with algorithmic selection in the first place for two of the gratifications, with some even for three dimensions. Figure 1 shows the distribution. On the $x$-axis, algorithmic appreciation is approved and on the $y$-axis the percentage of respondents in each category is displayed.

To explain algorithmic appreciation for news selection, we asked people about their news gratification. We measured this using the scale of Diddi and LaRose (2006). This scale consists of five dimensions: Habit strength, Surveillance, Escapism, Pass Time, and Entertainment. For each of the 23 items, the respondents were asked on a 7-point Likert scale to what extent people thought a statement on news consumption was applicable to them, ranging from 1 (not at all applicable) to 7 (very much applicable). In the next step, we used a principal components factor analysis using varimax rota- tion, similar to Diddi and LaRose (2006). Each dimension itself has a high level of reliability: (a) Entertainment consists of 2 items with a Cronbach's $\alpha$ of 0.77 ; (b) Escapism consists of 5 items with a Cronbach's $\alpha$ of 0.85 ; (c) Habit Strength consists of 4 items with a Cronbach's $\alpha$ of 0.84 ; (d) Pass Time consists of 5 items with a Cronbach's $\alpha$ of 0.87 ; (e) Surveillance consists of 7 items with a Cronbach's $\alpha$ of 0.85 .

Figure 2 shows the distribution for each dimension for news gratification. On the $x$-axis the 7-point scale for each news gratification is displayed, and the $y$-axis shows the percentage of respondents in each category. All gratifications have means showing that the majority of respondents thought they apply to them, with surveillance being the most sought-after gratification (Entertainment: $\mathrm{M}=3.91, \mathrm{SD}=1.73$; Escapism: $\mathrm{M}=3.59$, $S D=1.65$; Habit Strength: $M=4.31, S D=1.60$; Pass Time: $M=3.83, S D=1.65$; Surveillance: $M=4.78, S D=1.37$ ). In general, respondents in the US sample had higher values at the end of the scale, and Dutch samples had higher values at the start of the scale.

Our study explores the mechanism of the third person effect driving the relationship between gratifications of the news and algorithmic appreciation. For that reason, we have used a moderator. As described in the theory section, the third person effect, in this case, is conceptually close to what is also called epistemic overconfidence (e.g., see Kim, 2018; Salmon et al., 2019; Wei et al., 2007). We measured epistemic overconfidence using a Cognitive Reflection Test (CRT) based on the scale developed by Thomson and Oppenheimer (2016) combined with the three standard CRT questions of Toplak et al. (2011). The 7 questions have high face validity, and, in order to address some criticisms of the original CRT, do not require a high degree of mathematical sophistication to generate the correct answer. After the CRT we asked respondents to estimate how many questions they answered correctly, thereby assuming that

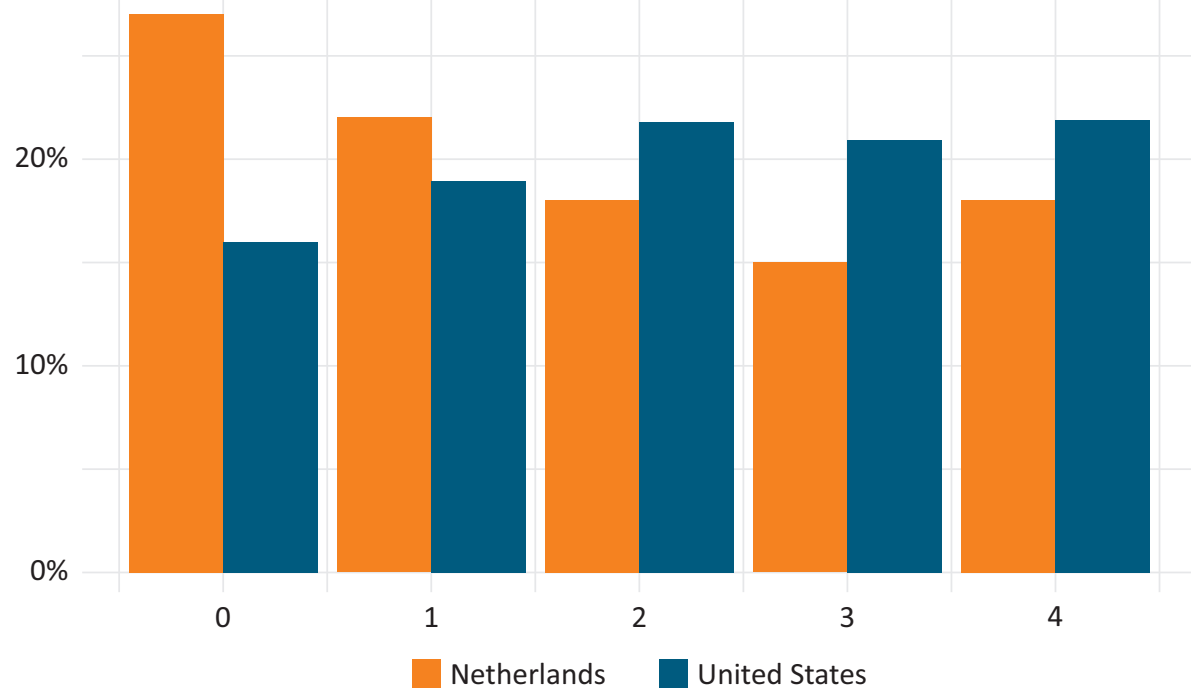

Figure 1. Descriptive information of the dependent variable. Notes: Mean $=1.92 ; S D=1.43$. 
Entertainment

Mean: 3.91, Standard Deviation: 1.73
Escapism

Mean: 3.59, Standard Deviation: 1.65

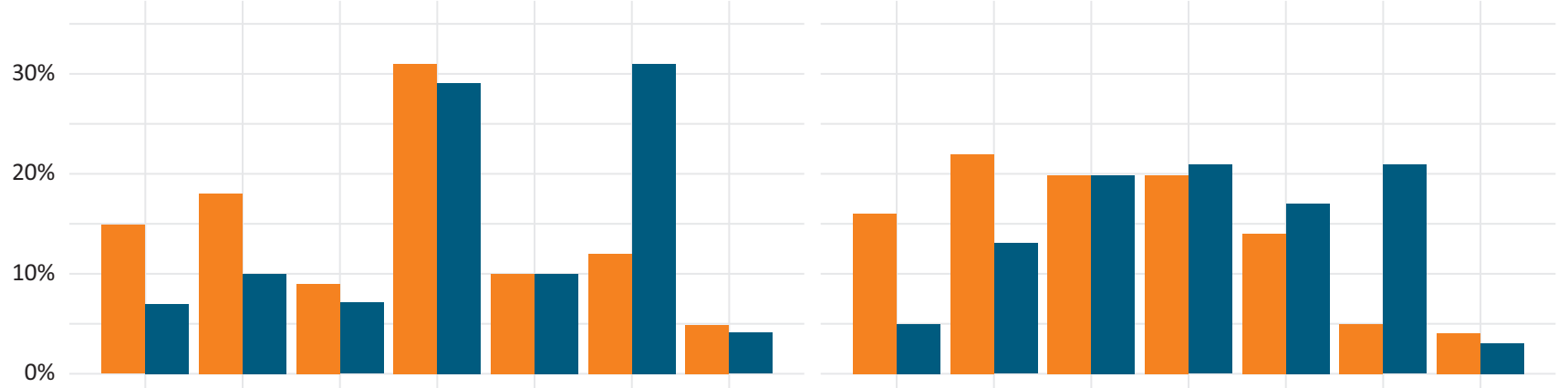

Habith Strength

Mean: 4.31, Standard Deviation: 1.60
Passing Time

Mean: 3.83, Standard Deviation: 1.65

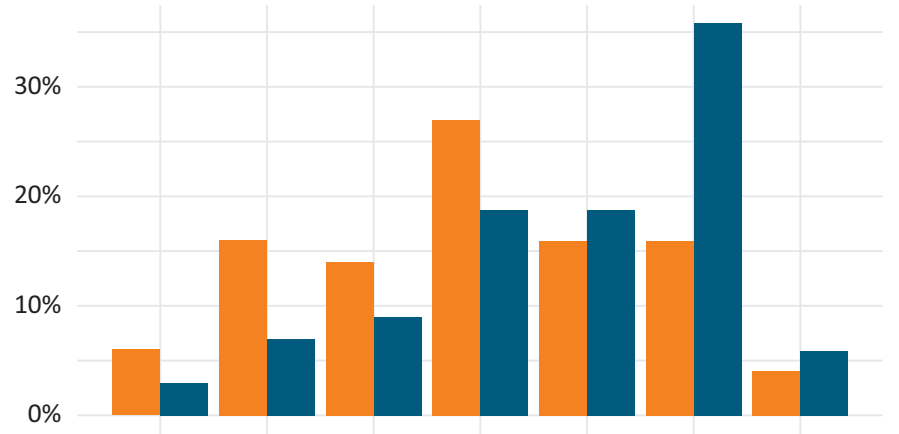

Surveillance

Mean: 4.78, Standard Deviation: 1.37

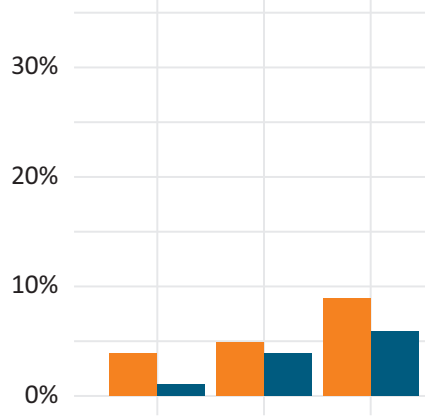

2

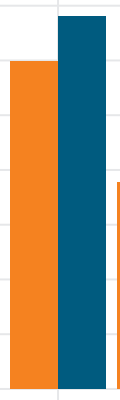

4

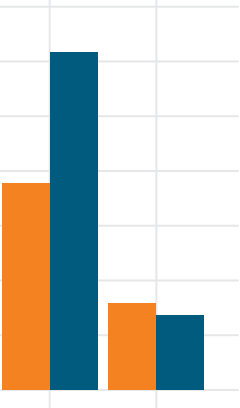

6

Netherlands

United States

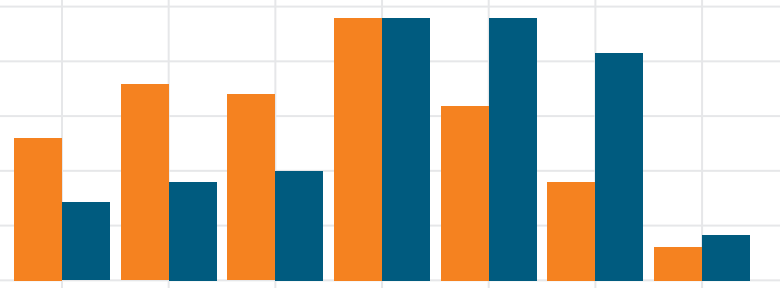

Figure 2. Descriptive information of the independent variables.

those that are overconfident give more intuitive (and thus false) answers while estimating that they have all or the majority of the questions correct. To measure epistemic overconfidence, we subtracted the number of correct answers people think they had given on the CRT to the actual number of correct answers. This could range from -7 (respondent answered all questions correct but estimated that none were correct) to 7 (respondent answered none of the questions correct but estimated that all were correct). Hence a higher number indicates higher levels of epistemic overconfidence, and 0 is the actual middle point (number of questions correctly estimated). On average, people overestimate their capabilities by 2 questions ( $M=2.48, \mathrm{SD}=1.96$ ), with $75 \%$ of the respondents ranging from slightly overestimating their capability (score of 1 ) to overestimating their capa- bilities by 4 questions (score of 4 ). The sample is slightly skewed towards people being overconfident, especially the majority in the Dutch sample was slightly overconfident (score of 2).

In our analysis, we controlled furthermore for Frequency of News Usage, Political Efficacy, and Trust in Media (see our online compendium for the visualization in the Supplementary Material). First, we measured Frequency of News Usage by asking respondents on an 8-point scale ( 0 being never and 7 being every day) how many days of the week they consume news in 5 different ways. The additive scale of the 5 items has a Cronbach's $\alpha$ value of 0.71 . On average, people consume news on approximately 4 days of the week ( $M=3.79$, $S D=1.63$ ). Second, we measured Political Efficacy (lowerleft panel in Figure 4) using a combined knowledge and 
efficacy seven-point scale, ranging from 1 (completely disagree) to 7 (completely agree). The additive scale of the 3 items has a Cronbach's $\alpha$ value of 0.57 . On average, people have a high level of political efficacy $(M=4.41$, $S D=1.28$ )-this is especially driven by the participants of the US sample. Third, we measured Trust in Media by asking respondents how much they (dis)agree with 9 statements regarding various gatekeepers on a seven-point scale, ranging from 1 (completely disagree) to 7 (completely agree). The additive scale of the 9 items has a Cronbach's $\alpha$ value of 0.85 ( $M=4.91, S D=1.10)$.

To test our hypotheses-i.e., whether algorithmic appreciation is dependent on the gratification of the news $(\mathrm{H} 1)$ and whether that relation is moderated by epistemic overconfidence $(\mathrm{H} 2)$-and to conduct exploratory analyses, we use OLS regression analyses (Bryman, 2016).

\section{Results}

\subsection{Which News Consumers Prefer Algorithmically Curated News?}

In this section, we start by exploring the bi-variate relationships between algorithmic appreciation and gratifications of the news. Figure 3 shows the level of algorithmic appreciation (Y-axis)-0 equals never the preferred gatekeeper, 4 equals always preferred gatekeeper-for

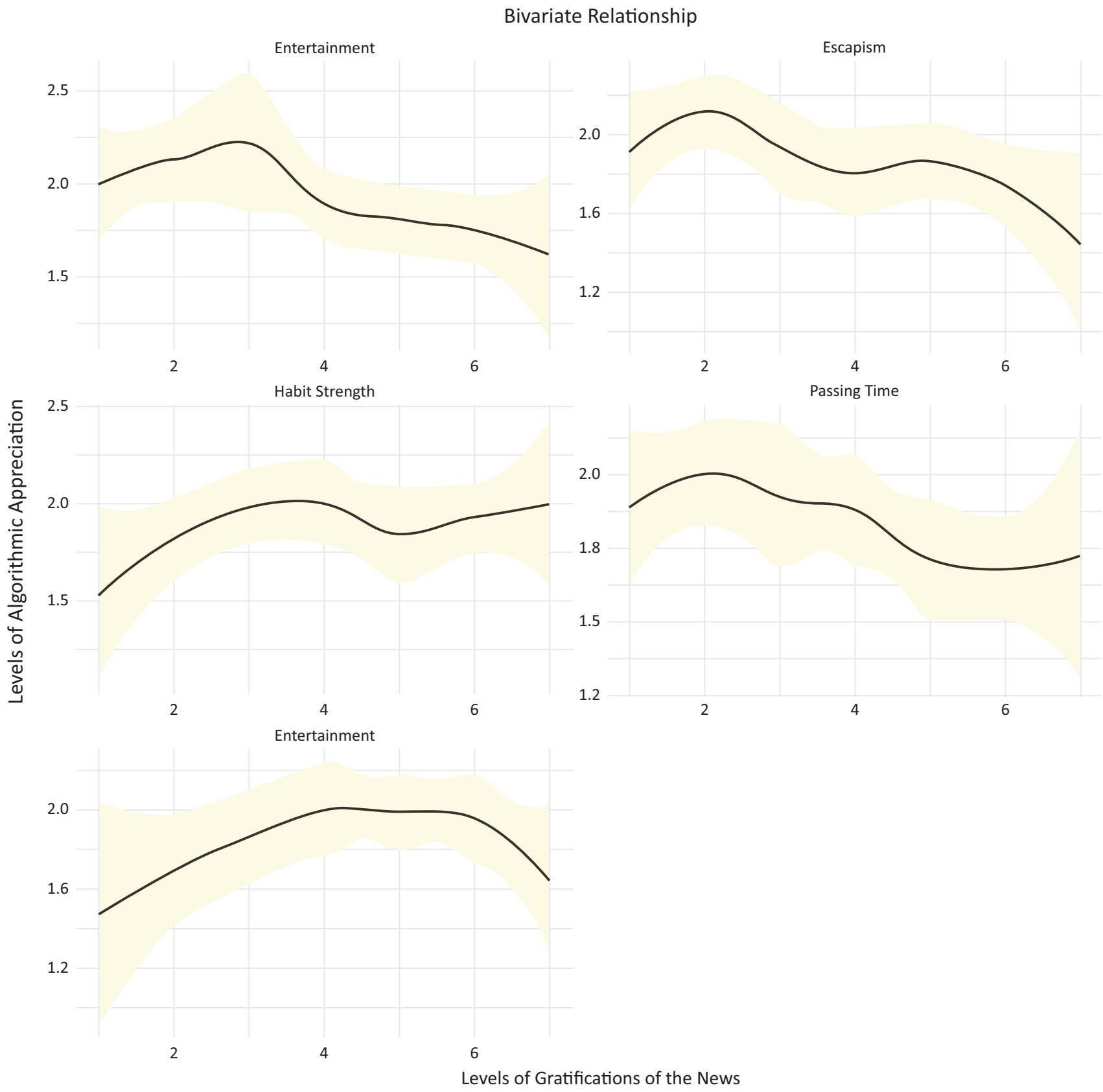

Figure 3. Bi-variate relations between algorithmic appreciation and gratifications of the news. 
each gratification (X-axis). The black solid line depicts a LOESS smoothening (locally weighted smoothing) to visualize the relationship between the two variables. The yellow area surrounding the line is the $95 \%$ confidence interval. As the panels for Entertainment (upper-left), Escapism (upper-right), and Pass Time (middle-right) of Figure 3 demonstrate, the relationship between these gratifications of the news and algorithmic appreciation is linear and negative. This means that the more you use news to entertain yourself, out of escapism, and/or to pass time, the less likely you are to appreciate an algorithmic gatekeeper (i.e., rank one of the two algorithmic news selections first). The middle-left panel of Figure 3 shows that there is no relationship (or a slightly positive one) between Habit Strength and Algorithmic Appreciation. The lower-right panel of Figure 4 shows that for Surveillance, the relationship is actually positive, but not linear: Meaning that the more you use to keep up-to-date with politics, the more often you rank an algorithmic gate-keeper first, except for when you use surveillance as a gratification all days of the week. This positive relationship is surprising and actually the opposite of what is hypothesized. Based on the theory, we had hypothesized that when the gratification sought for news is surveillance people will show less algorithmic appreciation (see $\mathrm{H} 1$ ).

To see whether this contradictory finding holds while controlling for other variables, we conduct an OLS regression. Figure 4 visualizes the regression effects, the full model is displayed in Model 1 of Table B1 in Appendix B (see Supplementary Material). As Figure 4 below shows, the news gratifications dimensions Escapism, Entertainment, and Passing Time have a negative, yet statistically insignificant, effect on Algorithmic
Appreciation after controlling for all the other variablesEntertainment is significant on a $10 \% \alpha$-level. Habit Strength and Surveillance have a positive effect on algorithmic appreciation, with both of them being statistically significant on the $10 \% \alpha$-level. This indicates opposite results for our $\mathrm{H} 1$, which stated people show less algorithmic appreciation for news selection when the gratification sought for news is surveillance compared to the other gratifications. None of the control variables have a statistically significant effect on algorithmic appreciation. We do see that on average, the US sample has higher levels of algorithmic appreciation than the Dutch sample.

In a second step, we interact gratifications of the news with epistemic overconfidence. In line with the recommendations of Brambor et al. (2006) and Holbert and Park (2019), we calculate and visualize the predicted effects and standard errors ( $\alpha$-level of $0.05 \%$ ) in Figure 5 . The full models are displayed in Model 2 till Model 6 of Table B1 and B2 in Appendix B (see Supplementary Material). Figure 5 shows that for the dimensions Habit Strength and Surveillance for the overconfident respondents, the more they use these gratifications for news sought, the higher levels of algorithmic appreciation they have. The opposite holds for insecure respondents. These interactions are statistically significant on the $10 \% \alpha$-level. We originally had preregistered the interactions to be considered significant at the $5 \%$, yet the authors' growing awareness of statistical power in interactions (e.g., Franzese \& Kam, 2009) led us to deviate from the pre-registered plan and report the $10 \%$ $\alpha$-level as support for our second ( $\mathrm{H} 2)$. For the dimensions of Entertainment, Escapism, and Passing Time, we do not observe a different trend for overconfident and insecure respondents.

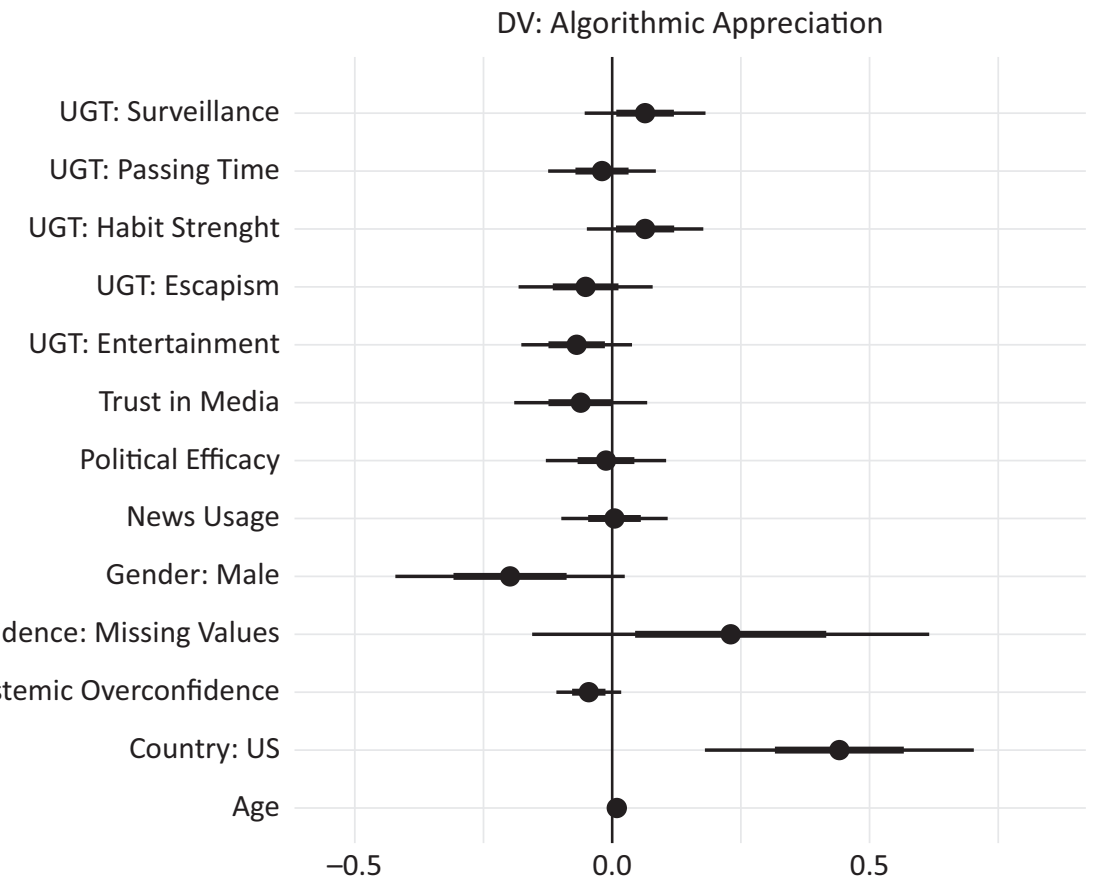

Figure 4. Predicting algorithmic appreciation. 


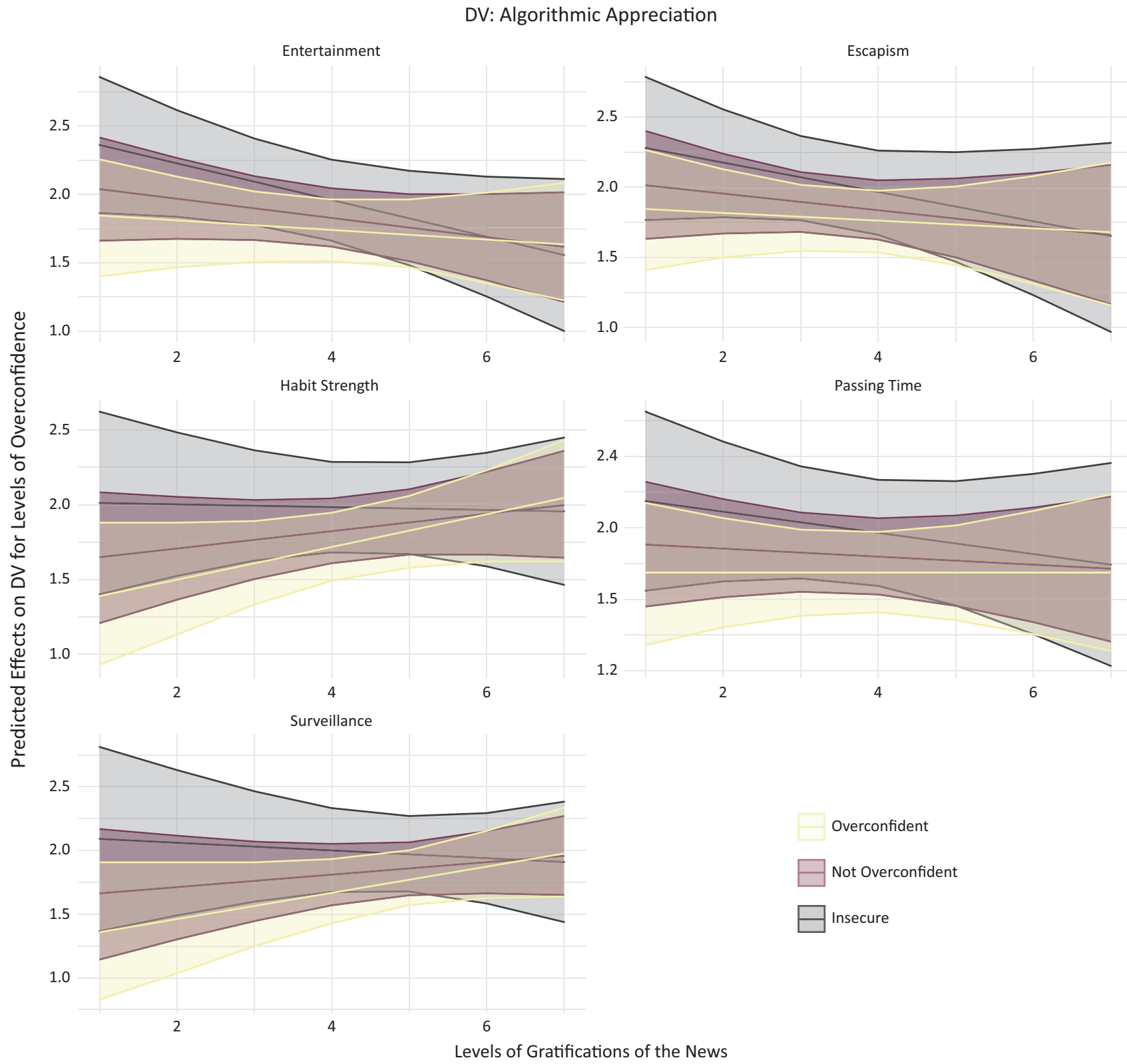

Figure 5. Predicting algorithmic appreciation for different levels of epistemic overconfidence.

\subsection{Exploratory Relationships}

To explore individual differences for appreciation of news selectors, we look at the role of gender in the relationship between overconfidence and algorithmic appreciation. Moreover, we look at how general trust in media coincides with appreciation for news selectors, and whether our proposed relationships in $\mathrm{H} 1$ and $\mathrm{H} 2$ also hold for the other types of news selectors.

\subsubsection{Gender}

While insufficiently powered to slice up the sample once more, Figure C1 in Appendix C (se Supplementary Material) demonstrates that patterns for female (lefthand panel) and male respondents (right-hand panel) are similar. Hence, the effect of $\mathrm{H} 2$ is not driven by (fe)males being more overconfident.

\subsubsection{Trust in Media}

The main analysis reported in Figure 4 demonstrates that the higher levels of generic trust in media, the lower the levels of algorithmic appreciation. Looking at the bi-variate relationships between news selectors ( $X$-axis) and trust in media ( $Y$-axis), Figure 6 demonstrates that for journalistic and algorithmic appreciation (top-left and bottom-left panel) the relationship is curve-linear. People with no and high levels of appreciation have lower trust in media. Most likely people who have high confidence in the journalistic system still prefer experts and journalists as gatekeepers compared to algorithmic 


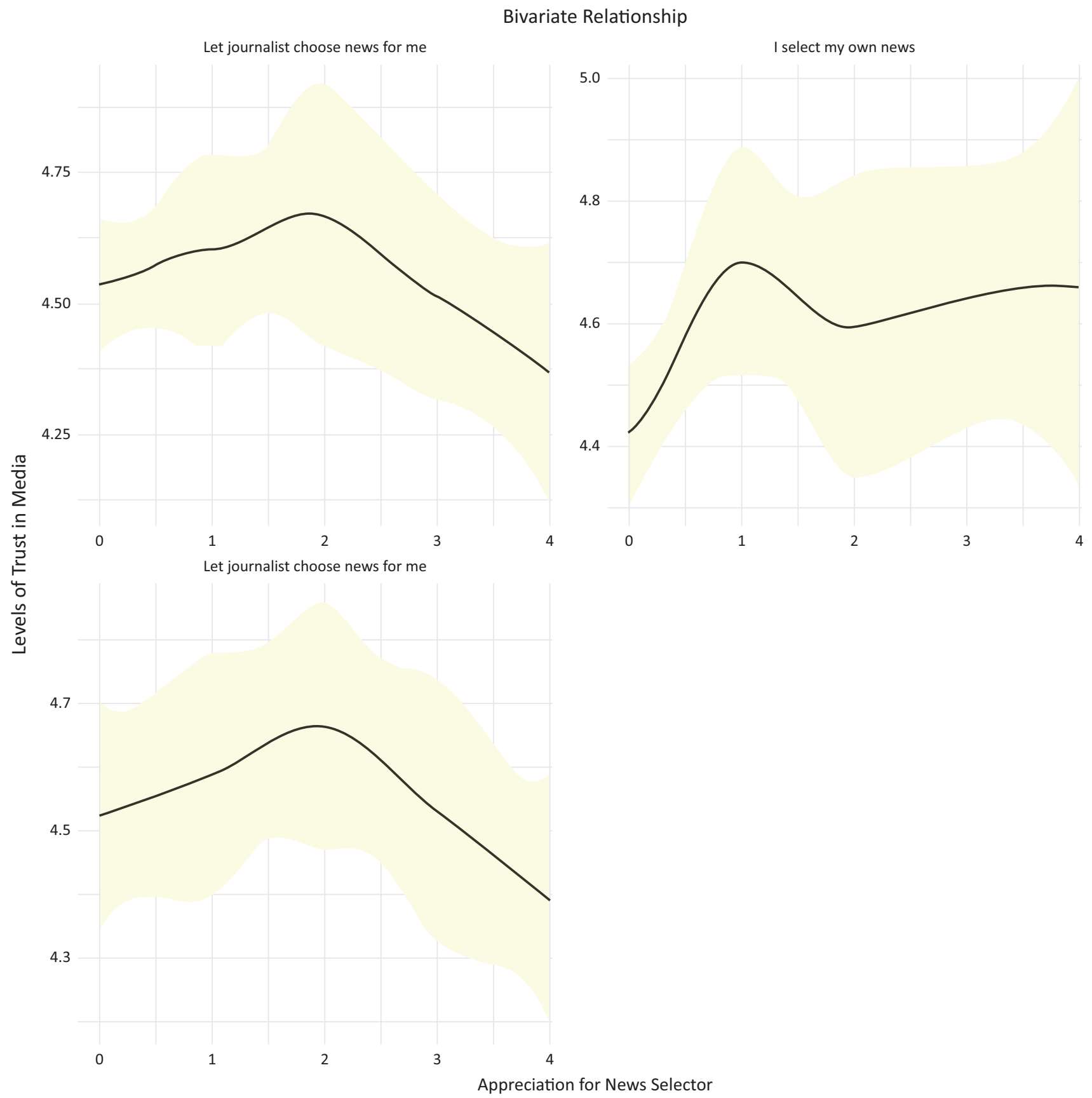

Figure 6. Bi-variate relations between news selectors and trust in media.

solutions. Additionally, there seems to be a group that has low levels of trust in all of the news selector options presented (traditional media or algorithms)-a group that likely proves to be interesting in the context of alternative media and sources.

When this bi-variate relationship is tested while controlling for additional variables in a regression analysis, Figure 7 (see also, Table C1 of Appendix C in the Supplementary Material) shows that for an $\alpha$-level of $10 \%$, compared to people who appreciate algorithmic news selectors, people who like to select their own news have higher trust in media. The same holds for people with higher levels of overconfidence. This exploratory result demonstrates that the role of overconfidence, or the third person effect, is potentially important to understanding how people think about news and particularly the ways in which the news is selected.

\subsection{Other News Selectors}

Lastly, we explore the relationship between UGT and the appreciation of other news selectors - the models can be found in Appendix $C$ in the Supplementary Material. Figure 8 demonstrates in the left-hand panel that for the UGT dimension Surveillance, there is a positive relationship between preferring to select your own news 


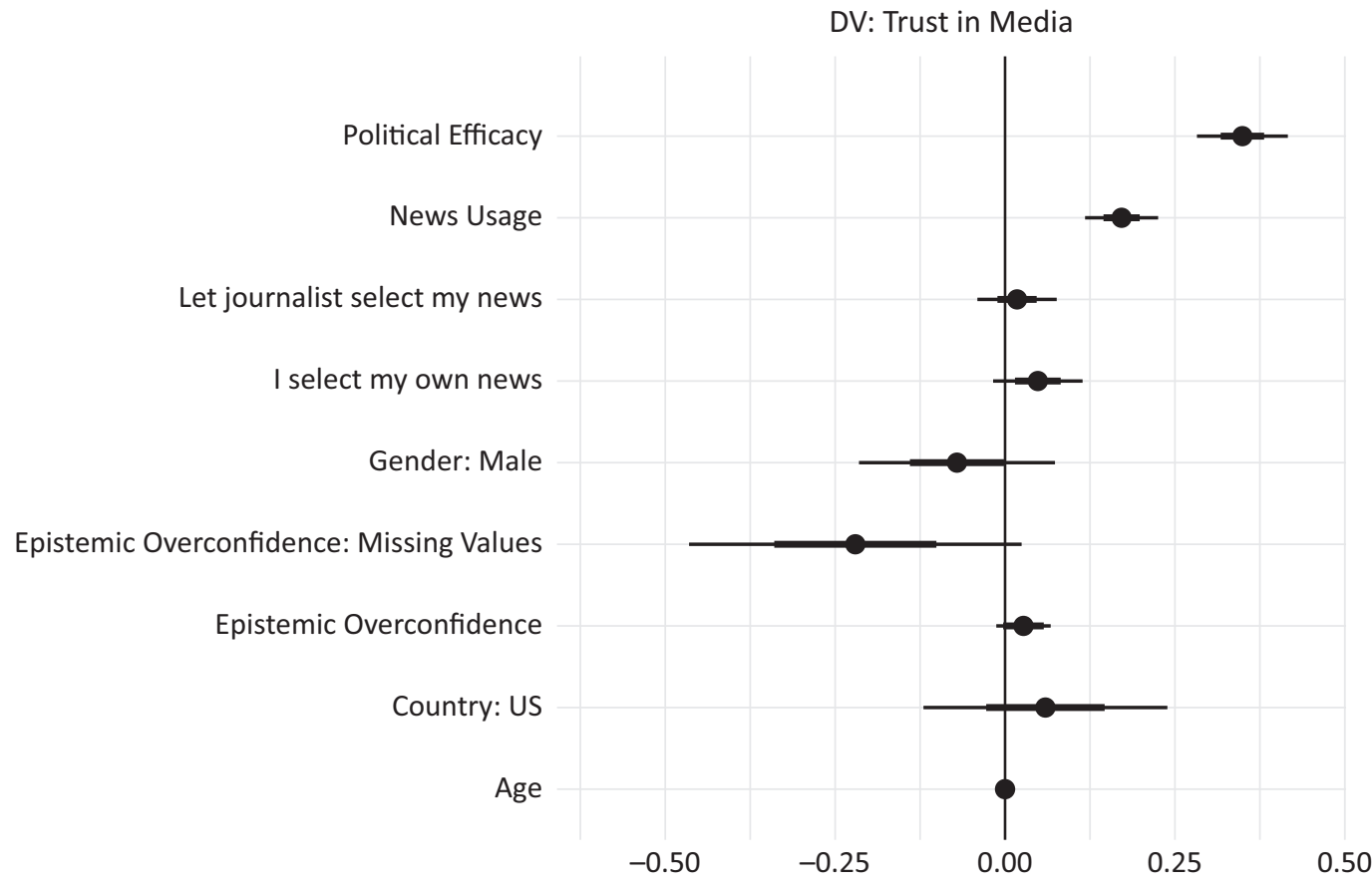

Figure 7. Predicting trust in media.

and using news for keeping up with politics. This indicates that the more you use the news to keep up-to-date with political information, the more you like to select the news yourself (significant at the $10 \% \alpha$-level). The relationship between UGT dimension Escapism and select- ing your own news as preferable is negative: The more you use the news for the gratification Escapism the less you prefer to select the news yourself (significant at the $10 \% \alpha$-level). The other dimensions center around 0 , indicating no effect. For appreciation of journalistic (human)

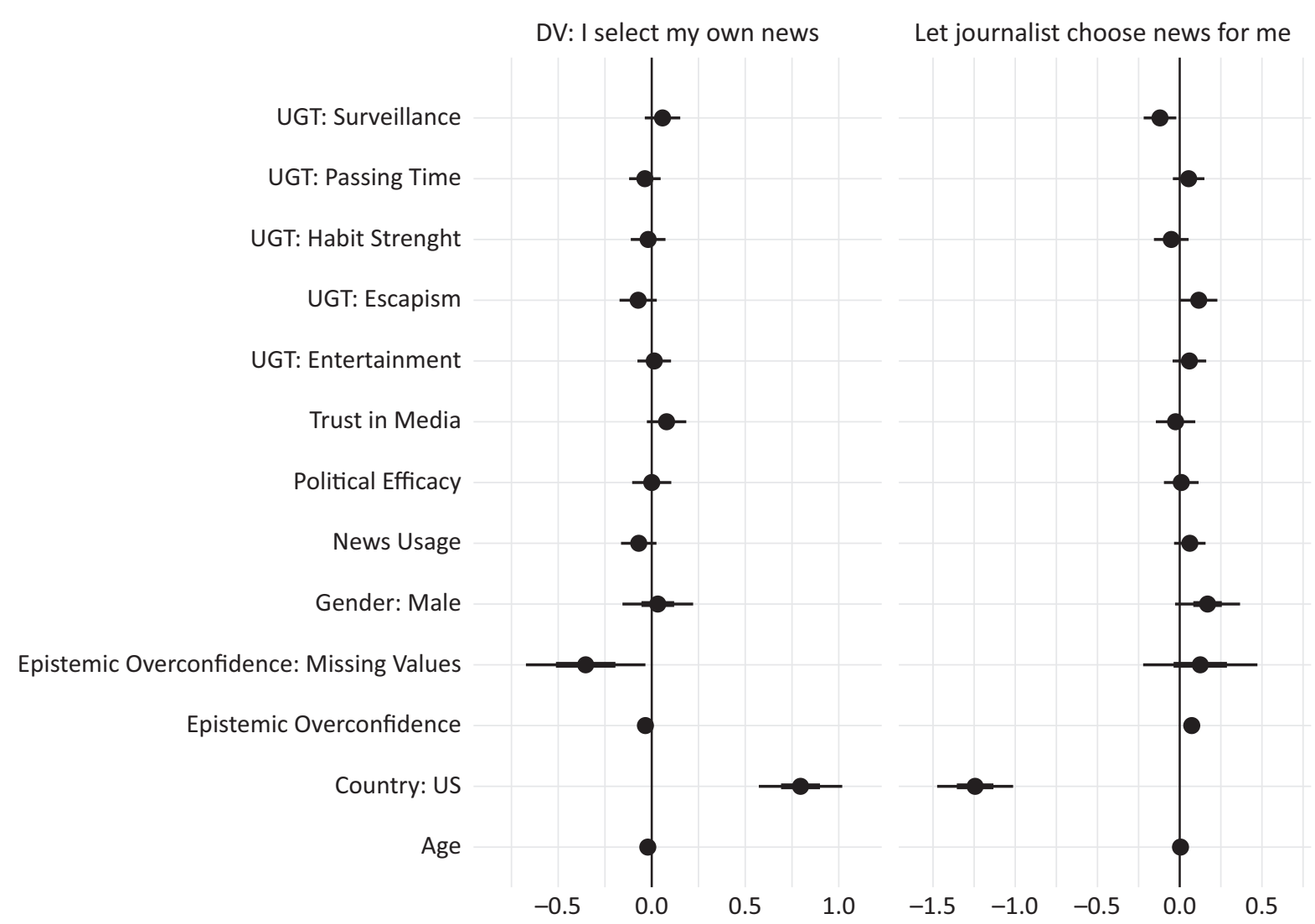

Figure 8. Predicting appreciation for other news selectors. 
selectors, the right-hand panel of Figure 8 shows that for the UGT dimension Surveillance and Habit Strength that the more you use the news as a strong habit and for keeping up with politics, the less you appreciate journalistic news selectors. You do have appreciation for these news selectors when the gratifications sought for are Passing Time, Escapism, and Entertainment.

Looking at the moderation of overconfidence for both other news selectors, Figure 9 shows that for respondents with high levels of overconfidence, they appreciate journalistic news selection less when using news more often for surveillance gratifications (bottomleft panel). Figure 10 demonstrates that overconfidence does not play a role for people who appreciate to self-select the news. Across all dimensions of UGT the patterns of insecure and overconfident respondents are similar.

\section{Discussion}

In this article, we investigated to what extent appreciation for algorithms as news gatekeepers is influenced by gratifications sought. We furthermore proposed that this relation is dependent on people's overconfidence in their cognitive abilities. Our analysis of 652 participants demonstrates that the gratifications the news is sought for matter for which gatekeeper people prefer for the selection of news articles. The main analysis (reported in Figure 6 and Table B1 in the Supplementary Material) demonstrates that the gratification of habitual

DV: Appreciation for Journalists as News Selector

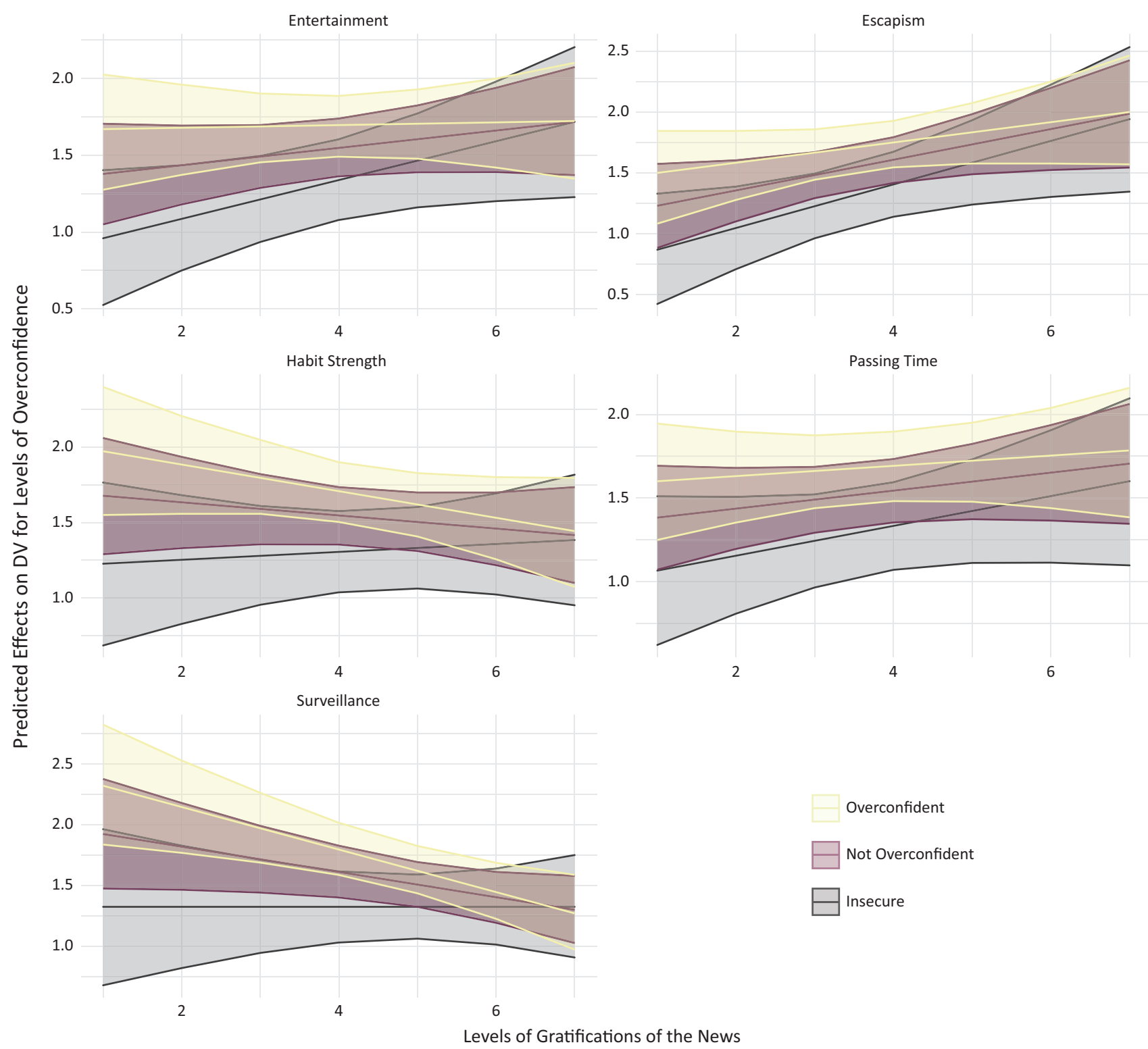

Figure 9. Predicting journalistic appreciation for different levels of epistemic overconfidence. 


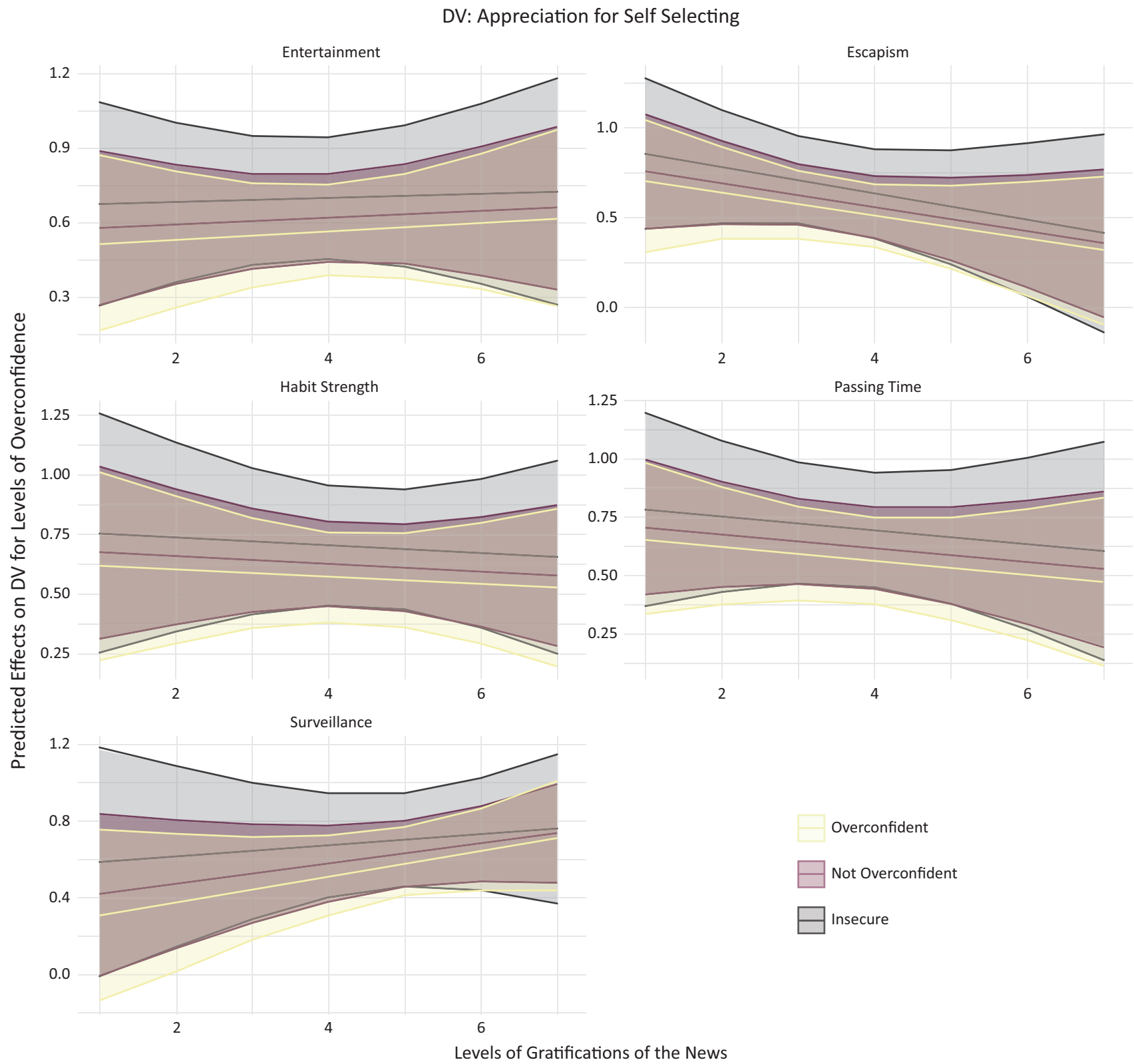

Figure 10. Predicting appreciation for self-selecting news for different levels of epistemic overconfidence.

news usage has a significant positive influence on algorithmic appreciation. This unexpected result might indicate that routine processes and frequent usage of news might depend to a larger extent on algorithmic gatekeepers than when news is consumed for other (more conscious) reasons. Algorithms mostly help consumers to make decisions easier and faster, thus they play a larger role when looking for news with no particular purpose. We hypothesized that when the main aim of news consumption is surveillance, the quality, accuracy, and diversity of information is of rather high importance for the user, calling for relying on expert judgments (i.e., journalists) for determining what is relevant. In contrast, when news consumption is aimed at passing time, entertainment, and escapism, getting information easier, faster, and more specifically targeted might play a larger role.
Therefore, the appreciation for expert (human) judgment should be higher when news is consumed for surveillance gratifications while for the other gratifications algorithmic gatekeepers are preferred. The results actually demonstrate the opposite: The more you consume news to pass time, escape from daily worries, or for entertainment, the less likely you are to prefer algorithmic news selection. However, for surveillance gratifications (keeping up with politics), algorithms are rather appreciated than feared. Two alternative explanations for those results come to mind: On the one hand, people get their news for passing time, escaping, or entertainment from platforms where they are less aware of the algorithmically curated processes (e.g., social media) or from preferred websites where the expert curation is key. Especially when it comes to entertainment, getting 
new and surprising content that possibly deviates from what was consumed before might be an added bonus. On the other hand, it might be that when the stakes are high (forming your political opinion) algorithms are seen as more "neutral" - in line with the machine heuristics, such that they can be trusted to not be influenced by anything other than the facts. This is of course a grave misconception of the nature and workings of news algorithms - depending on the (biased) data sources the algorithm was trained on and the design of the algorithm (what is it optimized for), algorithms can lead to biased or non-diverse sets of news recommendation. However, this conception might, especially in a polarized media environment, lead to more trust in an algorithm than in a journalist. Indeed we can see in our exploratory results that a negative relationship between using news for surveillance reasons and having a journalist as gatekeeper can be found. A general distrust in the media system and journalists to deliver "unbiased" news might bring people to rely even more on algorithmic gatekeepers when important information is concerned. Journalists can be trusted with the "soft side" of the news, but are seen as skeptical when it comes to providing political information.

Our second finding showcases that users with high levels of confidence in their own abilities are more likely to prefer algorithmic gatekeepers for surveillance gratifications, as we expected in Hypotheses 2. Highly confident-or overconfident-individuals might rather prefer to have a system that learns from their own decisions instead of having other people (i.e., journalists) decide upon their news consumption. The notion of algorithms being more "neutral" (as part of the machine heuristic), seeing them as passive amplifiers of one's own thoughts, might appear especially appealing to those estimating their own cognitive abilities as high. When expecting less of a negative influence on oneself, the notion of optimistic bias (being less vulnerable to malicious intents) has often been proposed as playing an important role (Salmon et al., 2019; Wei et al., 2007). Therefore, one's self-conception as being superior to others regarding the gullibility of negative effects can be seen as one main driver of the third-person effect.

While this small, and low-powered, study has given us some proof of concept for the puzzle of why people might prefer algorithmic news and at the same time fear a polarized and "filter bubbled" society, there are several limitations. First of all, the MTurk and Pollfish samples are not representative samples of the US and Dutch populations. In other words, we have to be careful when interpreting results. Moreover, while an interaction effect is able to give some indications for the mechanism underlying algorithmic appreciation, more evidence needs to be brought to the table. This will also involve looking more in detail at good measurements of preferences for gatekeepers-how much information do people get about the kind of gatekeepers (human or algorithmic) they can select from? In this study, we added additional explanations for the algorithmic gatekeepers to show based on which data selections could be madewhich already seems to imply a specific reasoning going beyond what human editors are doing. In how far the "motives" of selecting certain news should be included in the items or even systematically varied should be further explored, especially regarding the influences on trustworthiness or objectivity evaluations of the gatekeeper.

This study showed that in the context of gatekeeper preference often the question is less what specific conscious reasons people have to search for news but rather whether they follow habitual patterns instead of searching for particular gratifications. Given the cognitive load of more and more information, leaving the hard work of pre-selection to algorithms will likely gain in importance. However, we also showed that when users have specific goals in mind for their news search, different patterns of gatekeeper preferences occur-being moderated by variables such as confidence in one's own abilities, but also possibly related to trust in the media system. This opens two interesting avenues for future research: Firstly, understanding more about the relation of habitual usage and the use of algorithms as gatekeepers (algorithmic filtering as routine). Secondly, tapping into the gatekeeper decisions users make when they do have a specific purpose for their news search in mind and are thus possibly more likely to pay closer attention to the information they find. The exploratory analyses demonstrate that in order to better understand the preference for news selectors individual characteristics play an important role. Our study gives preliminary insights into this process. We argue that to better understand the relationship, more and higher-powered studies need to be conducted.

\section{Acknowledgments}

Earlier versions of this article have been presented at the CommunicatieEtmaal 2020 in Amsterdam, the ICA 2020 online version, and the VU Political Communication Research Group. We thank all participants for their useful comments and suggestions. We would also like to thank the editors of Media and Communication, and the journal's anonymous reviewers for the many constructive comments and suggestions. This work was supported by the Nederlandse Organisatie voor Wetenschappelijk Onderzoek [VI.Veni.191R.006].

\section{Conflict of Interests}

The authors declare no conflict of interests.

\section{Supplementary Material}

All data and analytical code can be found in the following links: https://github.com/MarikenvdVelden/EpistemicOverconfidence-in-Algorithmic-News-Selection; https://osf.io/2tqwy 


\section{References}

Blumler, J. G. (2019). Uses and gratifications research. In T. P. Vos, F. Hanusch, D. Dimitrakopoulou, M. Geertsema-Sligh, \& A. Sehl (Eds.), The international encyclopedia of journalism studies (pp. 1-8). Wiley. https://doi.org/10.1002/9781118841570.iejs0032

Bozdag, E. (2013). Bias in algorithmic filtering and personalization. Ethics and Information Technology, 15(3), 209-227. https://doi.org/10.1007/s10676013-9321-6

Brambor, T., Clark, W. R., \& Golder, M. (2006). Understanding interaction models: Improving empirical analyses. Political Analysis, 14(1), 63-82.

Bryman, A. (2016). Social research methods. Oxford University Press. vCarlson, M. (2019). News algorithms, photojournalism and the assumption of mechanical objectivity in journalism. Digital Journalism, 7(8), 1117-1133.

Choi, J. (2016). Why do people use news differently on snss? An investigation of the role of motivations, media repertoires, and technology cluster on citizens' news-related activities. Computers in Human Behavior, 54, 249-256.

Coppock, A. (2019). Generalizing from survey experiments conducted on mechanical turk: A replication approach. Political Science Research and Methods, 7(3), 613-628.

Davison, W. P. (1983). The third-person effect in communication. Public Opinion Quarterly, 47(1), 1-15.

Diddi, A., \& LaRose, R. (2006). Getting hooked on news: Uses and gratifications and the formation of news habits among college students in an internet environment. Journal of Broadcasting \& Electronic Media, 50(2), 193-210.

Dubois, E., \& Blank, G. (2018). The echo chamber is overstated: the moderating effect of political interest and diverse media. Information, Communication \& Society, 21(5), 729-745.

Dunning, D. (2011). The dunning-kruger effect: On being ignorant of one's own ignorance. In J. M. Olson \& $\mathrm{M}$. P. Zanna (Eds.), Advances in experimental social psychology (Vol. 44, pp. 247-296). Elsevier.

Franzese, R. J., \& Kam, C. (2009). Modeling and interpreting interactive hypotheses in regression analysis. University of Michigan Press.

Geiß, S., Magin, M., Jürgens, P., \& Stark, B. (2021). Loopholes in the echo chambers: How the echo chamber metaphor oversimplifies the effects of information gateways on opinion expression. Digital Journalism, 9(5), 660-686.

Gil de Zúñiga, H., Weeks, B., \& Ardèvol-Abreu, A. (2017). Effects of the news-finds-me perception in communication: Social media use implications for news seeking and learning about politics. Journal of ComputerMediated Communication, 22(3), 105-123. https:// doi.org/10.1111/jcc4.12185

Harari, Y. N. (2020, December 17). Als de wereld één grote samenzwering lijkt [What if the world looks like one big conspiracy]. de Volkskrant. https://www. volkskrant.nl/columns-opinie/als-de-wereld-eengrote-samenzwering-lijkt b061a6b9

Helberger, N. (2020, July 2). Challenging rabbit holes: Towards more diversity in news recommendation systems. Blogs LSE. https://blogs.Ise.ac.uk/medialse/ 2020/07/02/challenging-rabbit-holes-towardsmore-diversity-in-news-recommendation-systems

Holbert, R. L., \& Park, E. (2019). Conceptualizing, organizing, and positing moderation in communication research. Communication Theory, 30(3), 227-246.

Karimi, M., Jannach, D., \& Jugovac, M. (2018). News recommender systems: Survey and roads ahead. Information Processing \& Management, 54(6), 1203-1227.

Katz, E., Blumler, J. G., \& Gurevitch, M. (1974). The uses of mass communications: Current perspectives on gratifications research. SAGE.

Kim, J. W. (2018). They liked and shared: Effects of social media virality metrics on perceptions of message influence and behavioral intentions. Computers in Human Behavior, 84, 153-161.

Lee, A. M. (2013). News audiences revisited: Theorizing the link between audience motivations and news consumption. Journal of Broadcasting \& Electronic Media, 57(3), 300-317.

Lee, A. M., \& Chyi, H. I. (2015). The rise of online news aggregators: Consumption and competition. International Journal on Media Management, 17(1), 3-24.

$\mathrm{Li}, \mathrm{X}$. (2013). Innovativeness, personal initiative, news affinity and news utility as predictors of the use of mobile phones as news devices. Chinese Journal of Communication, 6(3), 350-373.

Logg, J. M., Minson, J. A., \& Moore, D. A. (2019). Algorithm appreciation: People prefer algorithmic to human judgment. Organizational Behavior and Human Decision Processes, 151, 90-103.

Nechushtai, E., \& Lewis, S. C. (2019). What kind of news gatekeepers do we want machines to be? Filter bubbles, fragmentation, and the normative dimensions of algorithmic recommendations. Computers in Human Behavior, 90, 298-307.

Newman, N., Fletcher, R., Levy, D., \& Nielsen, R. K. (2015). The Reuters Institute digital news report 2016. Reuters Institute for the Study of Journalism.

$\mathrm{Ng}$, Y.-L., \& Zhao, X. (2020). The human alarm system for sensational news, online news headlines, and associated generic digital footprints: A uses and gratifications approach. Communication Research, 47(2), 251-275.

Nisbett, R. E., \& Ross, L. (1980). Human inference: Strategies and shortcomings of social judgement. PrenticeHall.

Pariser, E. (2011). The filter bubble: What the internet is hiding from you. Viking.

Ricci, F., Rokach, L., \& Shapira, B. (2011). Introduction to recommender systems handbook. In F. Ricci, L. 
Rokach, \& B. Shapira, P. B. Kantor (Eds.), Recommender systems handbook (pp. 1-35). Springer.

Rose, K. (2019, June 8). The making of a youtube radical. The New York Times. https://www.nytimes.com/ interactive/2019/06/08/technology/youtuberadical.html

Ruggiero, T. E. (2000). Uses and gratifications theory in the 21st century. Mass Communication \& Society, 3(1), 3-37.

Salmon, C. T., Poorisat, T., \& Kim, S.-H. (2019). Thirdperson effect in the context of public relations and corporate communication. Public Relations Review, 45(2), Article 101823.

Schipper, N. (2020, November 3). Pizzagate, deep state, 9/11 en corona: Waarom complottheorie QAnon zo populair is [Pizzagate, deep state, 9/11 and Covid: Why the conspiracy theory QAnon is so popular]. Trouw. https://www.trouw.nl/cultuur-media/ pizzagate-deep-state-9-11-en-corona-waaromcomplottheorie-qanon-zo-populair-is $\sim$ bc19b11b

Shoemaker, P. J., \& Vos, T. (2009). Gatekeeping theory. Routledge.

Sundar, S. S. (2008). The main model: A heuristic approach to understanding technology effects on credibility. In M. J. Metzger \& A. J. Flanagin (Eds.), Digital media, youth, and credibility (pp. 73-100). MIT Press.

Sunstein, C. R. (2009). Republic.com 2.0. Princeton University Press.
Thomson, K. S., \& Oppenheimer, D. M. (2016). Investigating an alternate form of the cognitive reflection test. Judgment and Decision Making, 11(1), 99.

Thurman, N., Moeller, J., Helberger, N., \& Trilling, D. (2019). My friends, editors, algorithms, and I: Examining audience attitudes to news selection. Digital Journalism, 7(4), 447-469.

Toplak, M. E., West, R. F., \& Stanovich, K. E. (2011). The cognitive reflection test as a predictor of performance on heuristics-and-biases tasks. Memory \& Cognition, 39(7), 1275-1289.

Wei, R., Lo, V.-H., \& Lu, H.-Y. (2007). Reconsidering the relationship between the third-person perception and optimistic bias. Communication Research, 34(6), 665-684.

Welbers, K., van Atteveldt, W., Kleinnijenhuis, J., \& Ruigrok, N. (2018). A gatekeeper among gatekeepers: News agency influence in print and online newspapers in the Netherlands. Journalism Studies, 19(3), 315-333.

Wölker, A., \& Powell, T. E. (2020). Algorithms in the newsroom? News readers' perceived credibility and selection of automated journalism. Journalism, 22(1), 86-103.

Wong, J. C. (2020, June 25). Down the rabbit hole: How QAnon conspiracies thrive on facebook. The Guardian. https://www.theguardian.com/ technology/2020/jun/25/qanon-facebookconspiracy-theories-algorithm

\section{About the Authors}

Mariken van der Velden is an assistant professor of political communication in the Department of Communication Science at the Vrije Universiteit Amsterdam. She received her PhD in Political Science from the Vrije Universiteit Amsterdam. Her research interests comprise the areas of political communication, political behavior, and computational social science.

Felicia Loecherbach is a PhD candidate in the JEDS Tracking the Filter Bubble project at the Department of Communication Science at the Vrije Universiteit Amsterdam. She received her MA in Communication Science from the University of Amsterdam. She is studying the diversity of issues and perspectives in (online) news and how it is affected by recommender algorithms and selective exposure. 